\title{
الباحثون المشاركون في هذا العدد
}

عطاف أبو غُالي: أستاذ مشارك في الصحة النفسية، دائرة علم النفس، كلية التربية،جامعة الأقصى، غزة، فلسطين. eabughali2007@hotmail.com

سقُّان أبو نُمبالة: أستاذ في علم النفس، جامعة الأزهر، غزة، فلسطين. chrsd@palnet.com

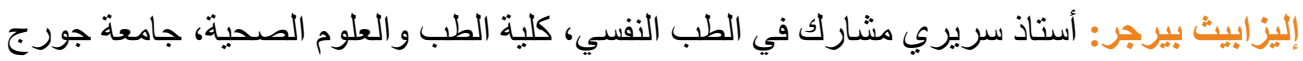
واشنطن، واشنطن، الولايات المتحدة الأمريكية. eberger@pmedonline.org

ميكيل بيدزبس-بارسيا: أستاذ في علم النفس، كلية علم النفس، جامعة غرناطة، اسبانيا. mperezg@ugr.es

أنطونيو بوينتي: أستاذ في علم النفس، جامعة كارو لاينا الشمالية، ولمنغتون، و الرئيس الحالي لجمعية علم النفس الأمريكية (APA).

Puente@uncw.edu

ماريو جالقزّ-لار ا: أستاذ مساعد في علم النفس، دائرة علم النفس، جامعة قرطبة، اسبانيا. mgalvezlara@gmail.com

سماح جِّز: أستاذ سريري مساعد في الطب النفسي الإكلينيكي، كلية الطب و العلوم الصحية، جامعة جورج و اشطن، واشطن، الولايات المتحدة الأمريكية. samahjabr@hotmail.con

شُّيزين عابدين: محاضر سريري في الطب النفسي، كلية الطب و العلوم الصحية، جامعة جورج واشنطن، واشنطن، الولايات المتحدة الأمريكية. Sabdeen@pmedonline.org 
ناهدة العرجا: أستاذ مساعد في علم النفس، دائرة العلوم الاجتماعية، جامعة بيت لحم، بيت لحم، فلسطين.

narja@bethlehem.edu

ضُباء عُنابيم: مختص علم النفس العصبي والعلاجي، المركز العربي للعقل و الدماغ و السلوك، سخنين، فلسطين. info@acmbb.org.il

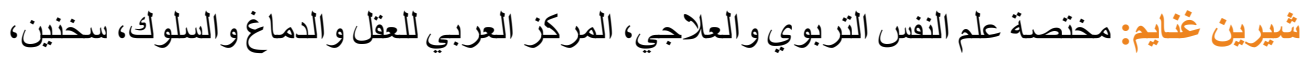
فلسطين. info@acmbb.org.il

أحمد فُفْوس: أستاذ مساعد في علم النفس، دائرة العلوم الاجتماعية، جامعة بيت لحم، بيت لحم، فلسطين. afasfous@bethlehem.edu

ر ركل فُبلاز لـوبزّ : أستاذ مساعد في علم النفس، كلية علم النفس، جامعة غرناطة، اسبانيا. rvilar@ugr.es

كائُّين لايهن: طالبة در اسات عليا، مركز الأبحاث الطبية، جامعة ستانفورد. kmlyman@stanford.edu

مايكل هورس: أستاذ مساعد في الطب النفسي، دائرة الطب النفسي، كلية العلوم الطبية، جامعة جورج تناون. Mmorse@pmedonline.org النجار : أستاذ مشارك في الصحة النفسية، جامعة الأقصى، غزة، فلسطين. ym.alnajar@alaqsa.edu

تثناليا هيدالهو- روز انتيهة: أستاذ مساعد في علم النفس، كلية علم النفس، جامعة غرناطة. nhidalgo@ugr.es 